\title{
THE INTERNET OF THINGS (IoT), ELECTRONIC HEALTH RECORD (EHR), AND FEDERAL LEGISLATION: THE CASE FOR A NATIONAL ELECTRONIC PERSONAL HEALTH INFORMATION (EPHI) RECORD SYSTEM
}

\author{
Raymond Angelo, Quinnipiac University, Raymond,angelo@quinnipiac.edu
}

\begin{abstract}
This paper reviews how the Internet of Things enables the electronic personal health record. Specifically, the Internet of Things utilizes high speed networks, cloud-based storage, and analytics, and the integration of real time medical information and data with hospital records. There is a discussion of how the electronic personal health record can improve patient care and physician performance and reduce the cost of health care. The US Congress has approved legislation to enable ePHI development, and penalties to individuals who engage in information blocking of health data exchange. The discussion concludes with a call to action for industry standards and for standards bodies to lead and monitor electronic personal health information systems development.
\end{abstract}

Keywords: electronic personal health record, electronic medical record, information blocking, cloud computing.

\section{INTRODUCTION}

On May 1, 2020 in the US Federal Register under Rules and Regulations, the Department of Health and Human services used the phrase ePHI, or electronic personal health information, to describe a revolutionary concept in patient medical information tracking and management (Grants, Contracts, and Other Agreements: Fraud and Abuse; Information Blocking, 2020). ePHI is the topic of this paper.

The current COVID-19 based pandemic has revealed some major flaws in our health care system, particularly with supply chain issues (Golan, Jernegan, \& Linkov, 2020); Ranney, Griffeth, \& Jha, 2020). But another long-standing issue with our health system is the lack of integration and accessibility for patients to patient health information. The authors indicated that the failure to develop an IoT based system of patient health information analysis has resulted in lost opportunity in better patient care and outcomes, clinical insights based on big data, and reducing costs for health care (Bates et al., 2014).

Sunyaev, Chornyi, Mauro and Krcmar (2010) described the Personal Health record (PHR) (or, as we will refer to it, ePHI record) as a vendor agnostic, evaluation framework, end user technology for managing information in healthcare. The ePHI record can serve as a starting point for requirements analysis for healthcare systems. By giving patients access to their integrated health information, care can become more efficient and effective by giving patients greater information and some leverage in the management of symptoms, while positively affecting the dynamics between physician/patient regarding treatment decisions.

One of the enablers of ePHI record is data captured by wearable eHealth devices. The global eHealth or Health Informatics market is expected to be over 300 billion dollars in North America by 2022 and allows anyone to monitor their own health status everywhere (Zhang \& Poslad, 2018). Personal health data can be accessed from two basic sources: database and other records from facility and health care provider visits and real time data from electronic capturing devices or sensors. Personal health records are person-centric records, and can be distinguished, yet built, from electronic medical record systems. The Federal Health Insurance Portability and Accountability Act of 1996 (HIPAA) stipulates that patients have a right access of their medical records, although the specific manner of access remains complicated. An ePHI record has been difficult for patients to assemble since each visit to a medical record provider contains a separate and distinct electronic health record. To build a comprehensive record frequently requires requests from many providers, since electronic medical records are institution based (e.g. from hospitals, clinics, doctor's offices, emergency care facilities, outpatient facilities). Electronic medical record systems can capture medical information from many sources and departments in a facility, such as patient demographics, clinical history, medication prescriptions, diagnostic imaging, laboratory studies, general physicals, cardiac care, 
emergency care, pulmonary care, notes, pharmacy information, and other aspects of medical care (Cuesta \& Weiler, 2017). To build an ePHI record requires extraction of individual information from these systems.

\section{THE IoT AND ePHI RECORD ENABLEMENT AND ARCHITECTURAL COMPONENTS OF IOT BASED ePHI RECORD}

The combination of facility records and real time date enables the construction of an ePHI record and affords patients the opportunity to manage their own health care. Bhat, Ahmad, Amin, and Ashraf (2017) discussed the technology and innovation that should be adopted to improve access to quality health care services for patients, while indicating that "the long-predicted IoT revolution in healthcare is already underway" (p. 258). Their work and the work of others discussed IoT technology that can use sensors and RFID wireless access to build electronic medical records or create a virtual link from anywhere to repositories of amassed data from these sensors. A virtual link eliminates the need to download these masses of data to an ePHI record. In the authors' view ePHI records can be an e-Health solution that is used to manage the health information of patients in various connected databases or a centralized database. The fact is with the proliferation of electronic medical record systems, real time health monitoring through sensors, broadband access to data, and cloud storage, the IOT based ePHI record systems can be technically realized.

\section{Cloud Computing}

Cloud computing provides computing storage and application power that is accessed on-demand at remote centers across the Internet. Darwish et al. (2019) argued that cloud computing and the Internet of Things have emerged as new interactive platforms and the adoption of the CloudIoT paradigm in the healthcare field can bring advanced opportunities for care to medicine. Cloud computing offers virtualized computing, storage, and networking resources over the Internet to the organizations and individual users in a dynamic way that allows analysis of big data for treatment of "new diseases", i.e. COVID-19 coronavirus. Aiming at maximizing the capabilities of IoT in healthcare systems, researchers and organizations have been devoted to the development of IoT-based technology (Bui and Zorzi, 2011; Manogaran et al., 2017; Manogaran et al., 2018; Sundmaeker et al., 2010).

Manogaran et al. (2017) discussed the recent use of big data analytics in the healthcare Internet of Things and communications environments that feature machine-to-machine communications. While pointing out that the IoT global IoT market value will reach 8.9 trillion USD by 2020, and that $7 \%$ of the total market value comes from the healthcare sector, Dang et al. (2019) conducted a survey on IoT and cloud computing for healthcare, while promoting the use of edge devices to manage big data in healthcare systems.

\section{Edge Devices}

Edge devices are storage and processing devices that "sit at the edge of a network" and include cached data to prevent redundant requests for data from application database systems. An edge device is any piece of hardware that controls data flow at the boundary between two networks in a cloud. Manogaran et al. (2018) contend that edge devices in managing health data can enhance patient care.

Healthcare is one of the application domains in IoT that draws enormous interest from industry, the research community, and the public sector. The development of IoT and cloud computing is improving patient safety and enabling more effective assisted living. In the healthcare industry the IoT connects all sorts of connected sensors and machines in an intelligent human -free network. The IoT and wireless communication technologies allow patient's health conditions to be streamed to human caregivers in real-time. Edge device computing is also called fog computing, or computing based on edge devices to perform data analytics on edge devices in real time, while improving data privacy, and reducing costs.

Thanks to the integration of IoT and cloud computing into the healthcare sector, health professionals can provide faster, more efficient and improved healthcare services, with regard to diabetes, asthma, heart disease, hyperthermia, Ebola, wheelchair management, rehabilitation, medication noncompliance among other diseases (Bates et al., 2014). 
Elhoseny et al. (2018) pointed out that applications in cloud-IoT health services applications are used to manage a big data; in particular, Industry 4.0 applications, which are combination of traditional manufacturing and industrial platforms and practices using current smart technology. For example, sensors are creating an extensive database continuously that is often referred to as Big Data. By using a cloud-based system data can be accessed from the sensors themselves, or from databases in large Internet based storage facilities. These applications have gained excellent research attention due to their need to analyze big data (sensor data) without human intervention. Most of the stakeholders prefer to use cloud computing in medical applications. Zakaria et al. (2019) espoused the benefits of cloud computing for healthcare IoT. An IoT cloud enabled healthcare system not only can process and store large amount of data, but can be retrieved by hospitals, doctors, patients, laboratories, pharmacists, and nurses leading to improvement in healthcare through improvement in communication and collaboration among these entities providing care (Tyagi \& Maheshwari, 2016).

\section{Embedded Devices (Sensors)}

Hu et al. (2017) characterized the Internet of Things (IoT) as the network of physical objects where information and communication technology connect multiple sources of information, and an important tool for managing health in an aging population. These authors indicated that according to the United Nations people over 60 years old account for $10 \%$ of the total population, while people over 65 years old represent seven percent of the total population. Between 2015 and 2050, the proportion of the world's population over 60 years will nearly double from $12 \%$ to $22 \%$. An aging society means increased attention to health issues, and a growing need for remote monitoring of certain critical bodily functions for the aging population. Hu et al. (2017) also discussed the prevalence of embedded devices, such as wearable sensors. With the rapid development of the Internet of Things (IoT), medical sensors, and Internet applications, online medical service has become more viable. By using the Internet for collecting and exchanging data, more precise and timely monitoring of symptoms occurs, providing an aging population and any individual with more flexible service, without the need to visit hospitals. While advocating the advantages of the sensor-cloud model, these authors do warn about security threats. As with all data, security needs to be taken into consideration. Any system should be based on intelligent and secure health monitoring scheme using IoT sensor based on cloud computing using proven authentication, encryption, and authorization techniques (Angelo, 2019).

Many authors have discussed the advantages of sensors or other medical device collectors (Bagheri \& Movahed, 2016; Choi and Shin, 2018; Jaimini, 2017; Kalarthi, 2016; Manogaran et al., 2018). Jaimini (2017) has pointed out that the IoT device market in healthcare will increase to $\$ 117$ billion by the end of 2020 . The volume of health-care data reached 150 exabytes in 2017. The author contended that professionals could use these low-cost sensors and "consumer grade devices" for "continuous monitoring and management of patients, monitoring of the patient's personal, public and population-based health signals" (p. 1). Santos et al. (2014) presented the outline of a secure Internet of Things architecture aimed at establishing assisted living framework to be used by mobile health applications. The global solution presented is based on Radio Frequency Identification technology (RFID) and Electronic Product Code (EPC) normalization for the establishment of a unique identifier for each mobile health related item. On a note of caution Gupta (2017) pointed out that some medical devices can be supported by proprietary communications protocols and cannot participate in communication over the common Internet protocols (IP). As a result, many healthcare facilities have "islands" of data that cannot be shared and stored in a centralized location in an automated fashion.

\section{HEALTH CARE IMPROVEMENTS PROVIDED BY THE ePHI Record}

\section{Improvements in Patient Care}

Many authors have discussed the possible improvements in patient care through ePHI records. Kelly et el. (2020) cited the interoperability of electronic health records to eliminate fragmented care afforded with kidney failure, which is currently hindered by disparate primary care, specialists, hospitals, and dialysis facility electronic health record systems. They present a technical framework for an integrated system and called on the United States Centers for Medicare and Medicaid Service (CMS) to directly incentivize interoperability for dialysis patients, similar to the interoperability programs supporting Medicare. Tutty et el. (2019) pointed out that to make an EHR viable it must 
be designed to minimize physician administrative documentation requirements and integrated with APIs to other systems. Current legislation (see FEDERAL GOVERNMENT ENABLEMENT OF ePHI RECORD

below) should help to alleviate these burdens, if health care system designers and members of Congressional, lawmakers, regulators, policymakers, and administrators work together to that end.

Shield, Goldman, and Anthony (2010) showed that EHR implementation at an outpatient center in Rhode Island resulted in measurable advantages including just-in-time improvements and decreased physician time out of the examination room. The authors noted that in the large-scale adoption of health monitoring devices, health care and wellness "monitoring data are currently captured in an unprecedented scale" and resulted in significantly improved patient outcomes. (p. 325). Kang et al. (2019) studied nursing care in an IoT-based service in a university hospital and found improved patient care, particularly with continuous vital sign monitoring system, worker environmental monitoring system safety, and the efficiency of medical staff and hospital environments. These authors pointed out that to successfully introduce IoT services in a hospital, analysis of big data and streaming devices needs to be more integrated with the latest artificial intelligence technology. Adler-Milstein and Huckman (2013) pointed out that technical interoperability or the lack of shared meaning and unusable delivery to physicians, provides limits to integration. Lack of standards for conformance testing, validation, and transparency continues to hinder information exchange. These practices are a form of information blocking, a phenomenon discussed below (see IoT AND INFORMATION BLOCKING AND THE FEDERAL GOVERNMENT). Vendors play a key role in the success of an organization's implementation of their EHR product and resulting provider efficiency. Shameer et al. (2017) defined precision medicine as the prevention and treatment strategies that take individual variability into account. Implementing precision medicine in a clinical setting requires integration of data from clinical evaluations, genomics, and physiological profiling to characterize an individual patient's disease progression. Implementing precision medicine practices requires integration data from both healthy and diseases states individuals and can hold unprecedent improvements in patient outcomes.

\section{Improvements in Patient Performance}

Bates et al. (2014) reported on the use of big data to reduce the cost of health care. Bates' study illustrated six use cases of big data to significantly decrease the costs of patients care, triage, readmissions, adverse events, decompensation, and treatment optimization for diseases affecting multiple organ systems. Hunt et al. (1998) systematically reviewed controlled clinical trials assessing the effects of computer-based clinical decision support systems on physician performance and patient outcomes. Their reviews covered the years 1974 to 1992 by searching the medical databases. Physician performance were assessed in 65 studies and 43 found a benefit (66\%), while six of 14 studies assessing patient outcomes found a benefit. Cuesta \& Weiler (2017) argued that healthcare environments with an abundance of medical devices tended to improve safety by providing real time insights into patient conditions, accuracy in care delivery, and timely and effective actions in support of patient care. The authors contended that IoT technology has enabled flexibility, scalability, and portability in nearly every care environment, and workflow associated with the patient and have become essential to healthcare providers.

\section{Reductions in the Cost of Health Care}

Wang et al. (2003) performed a cost benefit analysis of electronic medical records in primary care. The studies were sponsored by Partner's HealthCare System, Brigham and Women's Hospital, the Department of Ambulatory Care and Prevention (LAP) at Harvard Medical School, and Harvard Pilgrim Health Care, all located in Boston. Data were obtained from studies and the published literature. The authors found that an implementation of an electronic medical record system in primary care can result in a positive financial return on investment to the health care organization. Cost benefit analysis of electronic medical record usage by primary care physicians in an ambulatory care setting during a five-year period showed reductions in drug expenditures, improved utilization of radiology tests, improvements in charge capture, and decreased billing errors. Nalini and Suvithavani (2017) found that general advantages of IoT based ePHI record system with data analytics can result in improved standards in public health, patient profile analytics, genomic analytics, fraud analysis and safety monitoring. Dimitrov (2016) and Kuroda (2018) showed that technologies can reduce overall costs for the prevention or management of chronic illnesses. These include devices that constantly monitor health indicators, devices that auto-administer therapies, or devices that track real-time health data when a patient self-administers a therapy. 
Dimitrov (2016) postulated a "new category of personalised preventative health coaches" (Digital Health Advisors) will emerge. The author projected that by $2020,40 \%$ of IoT-related technology will be health-related making up a $\$ 117$ billion market. The "convergence of medicine and information technologies, such as medical informatics, will transform healthcare as we know it, curbing costs, reducing inefficiencies, and saving lives" (p. 156). "Glaxo recently announced that it is investing in electroceuticals, bioelectrical drugs that work by micro-stimulation of nerves. J\&J has teamed up with Google to develop robotic surgery. In addition, they are collaborating with Philips on wearable devices such as blood pressure monitors. Novartis is working with Google on sensor technologies, such as the smart lens, and a wearable device to measure blood glucose levels” (p. 159).

\section{IoT AND INFORMATION BLOCKING AND THE FEDERAL GOVERNMENT}

With the emergence of the Internet, the IoT, ePHI record and electronic medical system, sensors, cloud computing, and big data analysis, it seems as if the primary thing that is truly impeding the wide spread implementation of ePHI record is something referred to as information blocking. Information blocking, in its simplest form, is the deliberate "practice by a health IT developer of certified health IT, health information network, health information exchange, or health care provider that to interfere with access, exchange, or use of electronic health information" (ONC Interoperability Final Rule Clarifies Information Blocking EHR Intelligence, 2020, p. 1).

In a report to the US Congress by the Department of Health and Human Services approximately 60 unsolicited reports of potential information blocking were reported to the Office of the National Coordinator for Health Information Technology (ONC) in 2014. (Report to Congress, 2015). In that 2015 report the Subcommittee on Labor, Health and Human Services, Education and Related Agencies, Committee on Appropriations not only produced a report on the extent of health information blocking, but pointed out that evidence suggests that certain business, technical, and organizational practices are likely to interfere with the exchange of electronic health information, particularly electronic medical record vendors. These practices included, but are not limited to, contract terms, policies, or other business or organizational practices that restrict individuals' access to their electronic health information, and charging prices or fees for data exchange, portability, and interfaces that make exchanging and using electronic health information cost prohibitive (Report to Congress, 2015).

\section{FEDERAL GOVERNMENT ENABLEMENT OF EPHI RECORD}

Reports to Congress concluded that information blocking is a serious problem and recommended

that Congress prohibit information blocking and provide penalties and enforcement mechanisms to deter these harmful practices. Information blocking is in direct contrast to the direction of the US federal government, which is working to enable an interoperable health system where electronic health information is available and can be shared as needed to support efficient and effective patient-centered care. (Report to Congress, 2015). So, Congress responded by enacting the Cures Act on December 13, 2016, with many provisions specifying a need for swift implementation. The Congress has been working for five years in the development of laws surrounding the interoperability of medical records, and to fight information blocking (Report to Congress, 2015) .

In 2017 lawmakers entered into the U.S. Code of Laws a law regarding Information blocking. The document further defined information blocking as a practice that usually used by health information technology developers or providers to likely interfere with, prevent, or materially discourage access, exchange, or use of electronic health information and stipulated that any individual or organization determined to have committed information blocking shall be subject to a monetary penalty for as much as $\$ 1,000,000$ per violation (US Code, 2020).

On February 9, 2018, the President signed into law the Bipartisan Budget Act of 2018. It was amended to increase the amounts of certain civil money penalties for informational blocking and included revise new authorities related to withholding Health and Human Services grants, contracts, other agreements from those engaging in information blocking. In terms of ePHI record enablement it established information sharing enablement through Application Programming Interfaces (APIs) to interface to systems and aggregate data brought into the ePHI record. It also sets conditions for continuous certification testing for real world tests of information blocking. In the end Health IT 
developers' are charged with developing an ePHI record that secure the fulfillment of patient access requests, as well as the identification and reporting on breaches. Specifications for "EHI export" certification requirement are fully described (2020-2025 Federal Health IT Strategic Plan, 2020).

On March 09, 2020 The Department of Health and Human Services (HHS) finalized the Office of the National Coordinator for Health Information Technology's (ONC) interoperability rule, aiming to provide patients with more control of their health data and to eradicate information blocking. United States Secretary of Health and Human Services Azar has lauded the rules and actions, as have some CEOs from various electronic medical record firms. (EHR Intelligence, 2020.).

The 2020-2025 Federal Health IT Strategic Plan stated that "federal partners will continue to play a role in ensuring that patients get access to their electronic health information and have the full transparency that they need to shop for care” (p. 4). It acknowledges all stakeholders in the healthcare sector will benefit from a fully connected health system that empowers patients, caregivers, and their healthcare providers to use and share electronic health information. (2020-2025 Federal Health IT Strategic Plan, 2020). In the plan Donald Rucker, National Coordinator for Health Information technology stated that “( $t$ )he digitization of the nation's healthcare system has resulted in greater accessibility of health information to patients and caregivers. Yet, the system's transformation is hindered by entrenched interests looking to prohibit access to that information” (p. 3). It is sobering that the report indicated that as of 2017, 80 percent of physician offices and 96 percent of acute care hospitals use ONC-certified health IT. However, "individual patients can use health IT (e.g., patient portals and patient-facing apps) to access their health information, track and manage treatment of their health conditions, and interact with healthcare providers" (p. 7), "yet (while) most healthcare providers and health systems now use electronic health records ... information captured in these systems often remains inaccessible to patients, caregivers, and healthcare providers across different settings" (p. 3). Equally as sobering is that while healthcare spending is increasing, health outcomes are not significantly improving. When compared to other high-income countries, the United States has a high rate of disease burden and worse mortality rates, and the "U.S. life expectancy decreased between 2016 and 2017 for the first time in decades" (p. 8).

Finally, on CMS.gov, there is a discussion of CMS Interoperability and Patient Access final rule. It includes policies that impact a variety of stakeholders. Recognizing that hospitals, including psychiatric hospitals, and critical access hospitals are on the front lines of the COVID-19 public health emergency, CMS is extending the implementation timeline for the admission, discharge, and transfer notification Conditions of Participation by an additional six months (CMS Interoperability and Patient Access final rule, 2020).

\section{CONCLUSIONS, CHALLENGES TO ePHI RECORD AND A CALL TO ACTION}

The 2020-2025 Federal Health IT Strategic Plan noted that "expanded reliance on health IT can potentially exacerbate health disparities at the individual and population levels due to unequal access to and use of technology among certain populations telehealth capabilities could bring new services to rural populations with a shortage of healthcare providers". It is time to convene government and private industry bodies to roll out a comprehensive plan for an equitable Internet bandwidth in the United States, not only to provide a more robust and secure platform for ePHI records and the Internet, but also for wide-spread telemedicine as enabled by cloud based sensor programs (2020-2025 Federal Health IT Strategic Plan, 2020). Kelly et al. (2020) called on the Centers for Medicare and Medicaid Service to directly incentivize interoperability for dialysis patients. CMS has been instrumental in designating penalties for information blocking. It is time for the government agencies to determine incentives for vendors for efforts around health care system interoperability, not just penalties for information blocking. Kelly et al. (2020) also revealed that challenges with using electronic health records continue to be among the top complaints of physicians, yet most physicians recognize the value. It is time for a concerted effort by vendors to eliminate the "grunt" work of managing ePHI record that is expected by physicians by discovering new technology methods to address these issues.

Finally, governing bodies in technology need to develop and adopt standards for the network communications, storage, and application interfaces, as espoused by the 2020-2025 Federal Health IT Strategic Plan between disparate health records systems. Standards allow for commercialization and compatibility of products that are 
needed for an ePHI Record. In the personal computing revolution of the last century, governing bodies fueled change. In 1984 the International Standards Organization released the network model called Open Systems Interconnection (OSI) Reference Model so that any interested party could develop standard personal computer and LAN based application, from applications to network interface cards. Open systems standards enable many versions of software and hardware to work interchangeably across vendor implementations. In 1984 a standard personal computer internal bus communication labeled ISA was adopted and became the communication standard layer between the instruction set and the circuitry in a personal computer, enabling many vendors to produce personal computers. In the 1990s The Institute of Electrical and Electronic Engineers (IEEE) developed a set of LAN standards for node to node communications on local area networks. These and other advances revolutionized the technology industry, from the "ground up". Technology needs accepted commercial standards to flourish. (35100 Open Systems Interconnection (OSI), 2020; Encyclopedia: ISA bus, 2020; IEEE 802 LAN/MAN Standards Committee, 2020).

Our health care system is in crisis. Our patient outcomes are worsening, while costs are escalating. New diseases are emerging. We have the technology, data, and a federal mandate to improve health care, in terms of efficiency, effectiveness and cost. We need integrated government and private agency partnership to realize a health system anchored in the electronic personal health record.

\section{REFERENCES}

2020-2025 Federal Health IT Strategic Plan, (2020). The Office of the National Coordinator for Health Information Technology Office of the Secretary, United States Department of Health and Human Services. Retrieved from https://www.omaha.org.cn/data/upload/ueditor/20200318/5e71975aae98c.pdf

35100 Open Systems Interconnection (OSI). (2020). ISO.org. Retrieved from https://www.iso.org/ics/35.100/x/

Adler-Milstein, J., \& Huckman, R. S. (2013). The impact of electronic health record use on physician productivity. The American Journal of Managed Care, 19(10),345-52.

Angelo, R. (2019). Secure protocols and virtual private networks: an evaluation. Issues in Information Systems, 20(3), 37-46.

Bagheri, M., \& Movahed, S. H. (2016, November). The effect of the Internet of Things (IoT) on education business model. In 2016 12th International Conference on Signal-Image Technology \& Internet-Based Systems (SITIS). 435441). IEEE. Naples, Italy.

Bates, D. W., Saria, S., Ohno-Machado, L., Shah, A., \& Escobar, G. (2014). Big data in health care: using analytics to identify and manage high-risk and high-cost patients. Health Affairs, 33(7), 1123-1131.

Bhat, M. I., Ahmad, S., Amin, A., \& Ashraf, S. (2017). e-Health with internet of things. International. Journal of. Computer Science and Mobile Computing, 6(6), 357-362.

Bui, N., \& Zorzi, M. (2011, October). Health care applications: a solution based on the internet of things. In Proceedings of the 4th international symposium on applied sciences in biomedical and communication technologies 1-5, Barcelona, Spain.

Choi, A., \& Shin, H. (2018). Longitudinal Healthcare Data Management Platform of Healthcare IoT Devices for Personalized Services. Journal of Universal Computer Science, 24,(9), 1153-1169.

CMS Interoperability and Patient Access final rule. (2020). CMS.gov Retrieved from https://www.cms.gov/Regulations-and-Guidance/Guidance/Interoperability/index 
Cuesta, F., \& Weiler, A. (2017). How the Internet of Things (IoT) can improve interoperability and clinical workflows in IV medication administration? Retrieved May 1, 2020 from https://archive.hshsl.umaryland.edu/bitstream/handle/10713/7999/Cuesta_IoTInMidicationAdmin_2017.pdf?sequen $\underline{\mathrm{ce}=1}$

Dang, L. M., Piran, M., Han, D., Min, K., \& Moon, H. (2019). A survey on internet of things and cloud computing for healthcare. Electronics, 8(7), 768.

Darwish, A., Hassanien, A. E., Elhoseny, M., Sangaiah, A. K., \& Muhammad, K. (2019). The impact of the hybrid platform of internet of things and cloud computing on healthcare systems: opportunities, challenges, and open problems. Journal of Ambient Intelligence and Humanized Computing, 10(10), 4151-4166.

Dimitrov, D. V. (2016). Medical internet of things and big data in healthcare. Healthcare informatics research, 22(3), 156-163.

Elhoseny, M., Abdelaziz, A., Salama, A. S., Riad, A. M., Muhammad, K., \& Sangaiah, A. K. (2018). A hybrid model of internet of things and cloud computing to manage big data in health services applications. Future Generation Computer Systems, 86, 1383-1394.

Encyclopedia: ISA bus.PCMag.com (2020). Retrieved at https://www.pcmag.com/encyclopedia/term/isa-bus

Golan, M. S., Jernegan, L. H., \& Linkov, I. (2020). Trends and applications of resilience analytics in supply chain modeling: systematic literature review in the context of the COVID-19 pandemic. Environment Systems \& Decisions, 1-22.

Grants, Contracts, and Other Agreements: Fraud and Abuse; Information Blocking. (2020). Department of Health and Human services, Office of Inspector General's Civil Money Penalty Rules. 25644 Federal Register / Vol. 85, No. 85 / Friday, May 1, 2020 / Rules and Regulations. 42 CFR Parts 1003 and 1005 RIN 0936-AA09. Retrieved from https://www.govinfo.gov/content/pkg/FR-2020-04-24/pdf/2020-08451.pdf

Gupta, N. (2017). How IoT Can Significantly Improve Healthcare in the Context of Smart City. Industrial Internet Consortium: 1-9, Needham, MA.

Hu, J. X., Chen, C. L., Fan, C. L., \& Wang, K. H. (2017). An intelligent and secure health monitoring scheme using IoT sensor based on cloud computing. Journal of Sensors, 2017, 1-11.

Hunt, D. L., Haynes, R. B., Hanna, S. E., \& Smith, K. (1998). Effects of computer-based clinical decision support systems on physician performance and patient outcomes: a systematic review. Journal of the American Medical Association, 280(15), 1339-1346.

IEEE 802 LAN/MAN Standards Committee. (2020). IEEE.org. http://www.ieee802.org/

Information Blocking (2020). HealthIT.gov. Retrieved from https://www.healthit.gov/topic/information-blocking

Jaimini, U. (2017, May). PhD Forum: Multimodal IoT and EHR based Smart Health Application for Asthma Management in Children. In 2017 IEEE International Conference on Smart Computing (SMARTCOMP),1-2). IEEE. Denver, Colorado.

Kalarthi, Z. M. (2016). A review paper on smart health care system using internet of things. International Journal of Research in Engineering and Technology, 5(03), 8084.

Kang, S., Baek, H., Jung, E., Hwang, H., \& Yoo, S. (2019). Survey on the demand for adoption of Internet of Things (IoT)-based services in hospitals: Investigation of nurses' perception in a tertiary university hospital. Applied Nursing Research, 47, 18-23. 
Kelly, Y. P., Kuperman, G. J., Steele, D. J., \& Mendu, M. L. (2020). Interoperability and Patient Electronic Health Record Accessibility: Opportunities to Improve Care Delivery for Dialysis Patients. American Journal of Kidney Diseases. 1-4.

Kuroda, T. (2018). Do We Still Need Electronic Medical Record?. European Journal of Biomedical Informatics 14(4), 1-2.

Manogaran, G., Lopez, D., Thota, C., Abbas, K. M., Pyne, S., \& Sundarasekar, R. (2017). Big data analytics in healthcare Internet of Things. In Innovative healthcare systems for the 21st century, 263-284. Springer, Switzerland.

Manogaran, G., Varatharajan, R., Lopez, D., Kumar, P. M., Sundarasekar, R., \& Thota, C. (2018). A new architecture of Internet of Things and big data ecosystem for secured smart healthcare monitoring and alerting system. Future Generation Computer Systems, 82, 375-387.

Nalini, N., \& Suvithavani, P. (2017). A Study on Data Analytics: Internet of Things \& Health-Care. International Journal of Computer Science and Mobile Computing, 6(3), 20-27.

ONC Interoperability Final Rule Clarifies Information Blocking EHR Intelligence (2020). Retrieved from https://ehrintelligence.com/news/onc-interoperability-final-rule-clarifies-information-blocking

Ranney, M. L., Griffeth, V., \& Jha, A. K. (2020). Critical supply shortages-the need for ventilators and personal protective equipment during the Covid-19 pandemic. New England Journal of Medicine, 382(18), e41.

Report to Congress, April 2015. (2015) Report on Health Information Blocking. The Office of the National Coordinator for Health Information Technology (ONC) Department of Health and Human Services Retrieved from https://www.healthit.gov/sites/default/files/reports/info_blocking 040915.pdf

Santos, A., Macedo, J., Costa, A., \& Nicolau, M. J. (2014). Internet of things and smart objects for M-health monitoring and control. Procedia Technology, 16, 1351-1360.

Shameer, K., Badgeley, M. A., MIoTto, R., Glicksberg, B. S., Morgan, J. W., \& Dudley, J. T. (2017). Translational bioinformatics in the era of real-time biomedical, health care and wellness data streams. Briefings in bioinformatics, 18(1), 105-124.

Shield, R. R., Goldman, R. E., Anthony, D. A., Wang, N., Doyle, R. J., \& Borkan, J. (2010). Gradual electronic health record implementation: new insights on physician and patient adaptation. The Annals of Family Medicine, 8(4), 316-326.

Sundmaeker, H., Guillemin, P., Friess, P., \& Woelfflé, S. (2010). Vision and challenges for realising the Internet of Things. Cluster of European Research Projects on the Internet of Things, European Commision, 3(3), 34-36.

Sunyaev, A., Chornyi, D., Mauro, C., \& Krcmar, H. (2010, January). Evaluation framework for personal health records: Microsoft HealthVault vs. Google Health. In 2010 43rd Hawaii International Conference on System Sciences (pp. 1-10). IEEE. Koloa, Kauai, Hawaii.

Tutty, M. A., Carlasare, L. E., Lloyd, S., \& Sinsky, C. A. (2019). The complex case of EHRs: examining the factors impacting the EHR user experience. Journal of the American Medical Informatics Association, 26(7), 673-677.

Tyagi, S., Agarwal, A., \& Maheshwari, P. (2016, January). A conceptual framework for IoT-based healthcare system using cloud computing. In 2016 6th International Conference-Cloud System and Big Data Engineering (Confluence) (pp. 503-507). IEEE. Andaman and Nicobar Islands · India

U.S. Code (2020). Title 42. THE PUBLIC HEALTH AND WELFARE. Chapter 6A. PUBLIC HEALTH SERVICE. Subchapter XXVIII. HEALTH INFORMATION TECHNOLOGY AND QUALITY Part C. Other Provisions. 
Section 300jj-52. Information blocking. $\quad$ Retrieved $\quad$ May 30,2020 from https://www.law.cornell.edu/uscode/text/42/300jj-52

Wang, S. J., Middleton, B., Prosser, L. A., Bardon, C. G., Spurr, C. D., Carchidi, P. J., Kittller, A., Goldszer, R., Fairchild, D., Sussman, A., Kuperman, ,G, and Bates, D. (2003). A cost-benefit analysis of electronic medical records in primary care. The American Journal of Medicine, 114(5), 397-403.

Zakaria, H., Bakar, N. A. A., Hassan, N. H., \& Yaacob, S. (2019). IoT Security Risk Management Model for Secured Practice in Healthcare Environment. Procedia Computer Science, 161, 1241-1248.

Zhang, X., \& Poslad, S. (2018, May). Blockchain support for flexible queries with granular access control to electronic medical records (EHR). In 2018 IEEE International Conference on Communications (ICC) (pp. 1-6). IEEE. Kansas City, KS. 